\title{
Synthesis of Organic Acid Doped Polypyrrole and Its Evaluation as a Novel Cathode Material
}

\author{
Pengju Guo ${ }^{1, *}$, Mengtian $\mathrm{Ci}^{2}$, Mayong Zhao ${ }^{3}$ \\ ${ }^{1}$ Shenyang University of Chemical Technology, Shenyang 110000, Liaoning Province, China \\ ${ }^{2}$ Shenyang University of Chemical Technology, Shenyang 110000, Liaoning Province, China \\ ${ }^{3}$ Shenyang University of Chemical Technology, Shenyang 110000, Liaoning Province, China \\ *E-mail: ppjuguo086@163.com
}

doi: $10.20964 / 2021.01 .52$

Received: 20 September 2020 / Accepted: 7 November 2020 / Published: 30 November 2020

Using pyrrole and benzene carboxylic acid as raw materials, composite materials (BeAcLi/PPy) were successfully prepared by redox method. The structures, morphologies and battery performances of PPy and the composite materials (BeAcLi/PPy) were obtained with FTIR, SEM, CV and EIS. Battery performances of PPy and composite materials (BeAcLi/PPy) were obtained with a constant charge/discharge current. Test results revealed that PPy and the composite materials (BeAcLi/PPy) had reversible redox processes from 2.0-4.0 V. The discharge specific capacities of BeAcLi/PPy (3:1) and BeAcLi/PPy (5:1) were 74.5 and $57.8 \mathrm{mAh} \cdot \mathrm{g}^{-1}$, respectively, as measured at $20 \mathrm{~mA} \cdot \mathrm{g}^{-1}$ between 2.0 and $4.0 \mathrm{~V}$; these results were evidently better than that of PPy $\left(29.7 \mathrm{mAh} \cdot \mathrm{g}^{-1}\right)$ under identical experimental conditions. Additionally, the rate performances and cycling performances of the composite materials significantly improved. The excellent electrochemical performances of composite materials were mainly due to the introduction of BeAcLi as a dopant, thereby improving the polarization of PPy. In addition, the prepared composite materials had a uniform and open loosely stacked structure, which was conducive for increasing contact area between electrode material and electrolyte. As a result, the availability of active material improved, and the electrochemical properties improved.

Keywords: Lithium-ion battery; Dopant; Pyrrole; Electrode material; Composite materials

\section{FULL TEXT}

(C) 2021 The Authors. Published by ESG (www.electrochemsci.org). This article is an open access article distributed under the terms and conditions of the Creative Commons Attribution license (http://creativecommons.org/licenses/by/4.0/). 